\title{
Physical Activity and Selected Cardiovascular Risk Factors in Middle-Aged Male Personnel of Self-Defense Forces
}

\author{
Hidenari SAKUTA ${ }^{1 *}$ and Takashi SUZUKI ${ }^{2}$ \\ ${ }^{1}$ Department of Internal Medicine, \\ ${ }^{2}$ Department of Research and Laboratory, Self-Defense Forces Central Hospital, Ikejiri 1-2-24, Setagaya-ku, \\ Tokyo 154-8532, Japan
}

Received January 12, 2005 and accepted September 14, 2005

\begin{abstract}
We cross-sectionally analyzed the association between duration of physical activity and the presence of selected cardiovascular risk factors in the middle-aged male personnel of the SelfDefense Forces who underwent retirement check-up $(n=974)$. In a univariate regression analysis, duration of high intensity physical activity but not that of moderate or low intensity physical activity inversely correlated with body mass index (BMI), triglyceride, fasting plasma glucose, white blood cell (WBC) count and systolic blood pressure. No intensity categories of physical activity correlated with total cholesterol. In a multivariate logistic regression analysis adjusted for lifestyle factors and the rank, the odds ratio per $1 \mathrm{~h} / \mathrm{wk}$ increase in high intensity physical activity was .88 (95\% confidence interval (CI) .80-.97; P=.007) for the presence of obesity $\left(\mathrm{BMI} 25.0 \mathrm{~kg} / \mathrm{m}^{2}\right), .88(95 \% \mathrm{CI} .81-.95 ; \mathrm{P}=$ $.002)$ for hypertrigly ceridemia, .87 (95\% CI .76-.99; $\mathrm{P}=.034)$ for type 2 diabetes, and $.90(95 \% \mathrm{CI}$ $.82-.99 ; P=.037)$ for hypertension. Neither hypercholesterolemia nor high $\mathrm{WBC}$ count $(\geq 6,900 / \mu \mathrm{l})$ was associated with high intensity physical activity. High intensity physical activity inversely correlated with traditional cardiovascular risk factors in the middle-aged men.
\end{abstract}

Key words: Physical activity, Cardiovascular risk factor, Obesity, Type 2 diabetes, Hypertension

\section{Introduction}

A number of risk factors for chronic diseases are precipitated by physical inactivity. Most prevalent chronic diseases have an association with physical inactivity ${ }^{1,2)}$. For instance, physically inactive person shows elevated risk of cardiovascular disease $^{3-5)}$ and premature death ${ }^{6,7)}$. The association between physical inactivity and cardiovascular disease can partly be explained on the basis of the unfavorable effects of physical inactivity on cardiovascular risk factors such as obesity ${ }^{8)}$, dyslipidemia $^{9,10)}$, type 2 diabetes $^{9)}$, hypertension ${ }^{11,12)}$ and high white blood cell (WBC) count ${ }^{13-15)}$. It is not established, however, whether low or moderate intensity physical activity has good effects on cardiovascular risk factors. Also, it is controversial whether high intensity physical activity exerts

\footnotetext{
*To whom correspondence should be addressed. Present address: Department of Education, GSDF Medical School, 1-224 Ikejiri, Setagaya-ku, Tokyo 154-8566, Japan
}

better effects on these parameters than low intensity physical activity beyond its contribution to "volume" of physical activity ${ }^{16,17)}$, which can be presented as a product of intensity, frequency and duration of physical activity. If low or moderate intensity physical activity does not affect cardiovascular risk factors, then volume of physical activity may not affect these factors. In the present study, we analyzed cross-sectionally the association between cardiovascular risk factors and duration of physical activity at each examination intensity level in male personnel of the Self-Defense Forces (SDFs).

\section{Materials and Methods}

Middle-aged male personnel of SDFs who underwent retirement check-up at SDFs Central Hospital were studied $(n=974)$. Mean age $( \pm$ SD) of the personnel was $52.9 \pm 1.0$ $\mathrm{yr}$ (range of age: 51-59 yr). Blood pressure, serum total cholesterol, triglyceride, fasting plasma glucose and WBC count were measured. Body mass index was calculated as 
[body weight $(\mathrm{kg})] /[\text { height }(\mathrm{m})]^{2}$. Obesity was defined as having body mass index of $25.0 \mathrm{~kg} / \mathrm{m}^{2}$ or more based on the new criteria of the Japan Society for the Study of Obesity ${ }^{18}$. Diagnosis of diabetes was made according to the criteria of the World Health Organization ${ }^{19)}$. Diagnosis of hypertension was made based upon individual medical history or takining medication for hypertension $(\geq 140 / 90 \mathrm{mmHg})$ based on the criteria of the Seventh Report of Joint National Committee on Prevention, Detection, Evaluation, and Treatment of High Blood Pressure ${ }^{20}$. Diagnosis of hypercholesterolemia and hypertriglyceridemia was made according to individual medical history and laboratory data; subjects with total cholesterol of higher than $5.69 \mathrm{mmol} / \mathrm{l}(220 \mathrm{mg} / \mathrm{dl})$ or taking medication for were defined as hypercholesterolemia, and triglyceride of $1.68 \mathrm{mmol} / \mathrm{l}(150 \mathrm{mg} / \mathrm{dl})$ or more or taking medication for triglyceride as hypertriglyceridemia. Subjects with WBC count of $6,900 / \mu \mathrm{l}$ or more (upper 20 percentile of the studied population) was defined as high WBC count.

Information about present lifestyle factors including daily number of cigarettes smoked, subjective vegetable intake, daily alcohol consumption, physical activity and rank in SDFs (officer/non-officer) was obtained using self-completion questionnaire and interview. Vegetable intake was assessed by the self-rating scale and classified into four categories: poor intake 1 , common intake 2 , relatively rich intake 3 , and rich intake 4 . In a regression analysis of the population studied "vegetable intake score" was positively associated with plasma folate levels which are rich in vegetables ( $\beta=.076, \mathrm{P}=.018$ ). Daily ethanol consumption ( $\mathrm{ml}$ ethanol/ day) was calculated from currently consumed volume of each type of alcoholic beverages. Low intensity physical activity was defined as such as walking, cycling in flat place and golf ( $<3.0$ METs (work metabolic rate/resting metabolic rate)), moderate intensity physical activity as such as slow jogging and baseball (3.0-6.0 METs), and high intensity physical activity as such as tennis, judo, jogging and swimming ( $>6.0$ METs) ${ }^{21-23)}$. The frequency of exercise enough to make a sweat was asked ${ }^{24)}$, which correlated with duration of high intensity physical activity $(\beta=.340, \mathrm{P}<.001)$ and that of moderate intensity physical activity $(\beta=.384$, $\mathrm{P}<.001)$ but not with that of low intensity physical activity $(\beta=.018, \mathrm{P}=.572)$ in the studied population. Informed consent was obtained from each subject. The study protocol was approved by the ethics committee of the hospital.

The continuous variables were given as mean \pm SD. Skewed variables (triglyceride and glucose) were presented as geometric mean values with $95 \%$ confidence interval. Univariate and multivariate linear regression analyses were performed with duration of each category of physical activity as dependent variables and levels of selected cardiovascular risk factors as independent variables. To obtain odds ratio per $1 \mathrm{~h}$ increment of the duration of each category of physical activity for the presence of selected cardiovascular risk factors, univariate and multivariate logistic regression analysis was performed. For the statistical analysis Stat View, ver. 5.0 (SAS Institute Inc., Cary, North Carolina, USA) was used.

\section{Results}

Characteristics of the subjects studied were shown in Table 1. Distribution of the duration of physical activity at each intensity level was shown in Fig. 1. Seven hundred and thirtyeight subjects $(75.8 \%)$ answered not doing high intensity physical activity, 413 subjects $(42.4 \%)$ not doing either moderate or high intensity physical activity, and 59 subjects (6.1\%) not doing any intensity of physical activity regularly.

Duration of high intensity physical activity was inversely associated with body mass index, triglyceride, fasting plasma glucose, WBC count and systolic blood pressure but not with total cholesterol in a univariate linear regression analysis (Table 2). Duration of moderate intensity physical activity was not associated with any parameters studied. Duration of low intensity physical activity was positively associated with body mass index but not with total cholesterol, triglyceride, fasting plasma glucose, WBC count, or systolic blood pressure. Similar results were observed for each intensity category of physical activity also in a multivariate regression analysis which included all intensity categories of physical activity, ethanol consumption, vegetable intake, daily number of cigarettes smoked and the rank in SDFs (officer/non-officer) (Table 3).

In a univariate logistic regression analysis, an increment in duration of high intensity physical activity was associated with the presence of obesity, hypertriglyceridemia, type 2 diabetes, high WBC count and hypertension but not with hypercholesterolemia (Table 4). Increment in duration of moderate intensity physical activity was inversely associated with the presence of hypertension but not with the presence of other cardiovascular risk factors studied. An increment in duration of low intensity physical activity was paradoxically positively associated with the presence of obesity, type 2 diabetes and hypertension but not with the presence of other cardiovascular risk factors studied. Similar results were observed in a multivariate logistic regression analysis which included all categories of intensity of physical activity, daily ethanol consumption, vegetable intake, daily number of cigarettes smoked and the rank in SDFs (officer/non-officer) (Table 5), except the inverse association between high intensity physical activity and high WBC count. The positive association between low intensity physical activity, type 2 diabetes and hypertension was lost in the multivariate analysis.

\section{Discussion}

It is controversial whether vigorous intensity physical activity confers additional benefit for decreasing 
Table 1. Characteristics of the subjects studied

\begin{tabular}{|c|c|c|c|c|c|}
\hline & $\begin{array}{c}\text { Physically } \\
\text { inactive } \\
\text { group }\end{array}$ & $\begin{array}{l}\text { Low } \\
\text { intensity } \\
\text { group }\end{array}$ & $\begin{array}{c}\text { Moderate } \\
\text { intensity } \\
\text { group }\end{array}$ & $\begin{array}{l}\text { High } \\
\text { intensity } \\
\text { group }\end{array}$ & $\begin{array}{c}\text { All } \\
\text { subjects }\end{array}$ \\
\hline $\mathrm{n}$ & 59 & 354 & 325 & 236 & 974 \\
\hline Age & $52.8 \pm 1.1$ & $53.0 \pm 1.1$ & $52.8 \pm 0.9$ & $53.0 \pm 1.1$ & $52.9 \pm 1.0$ \\
\hline \multicolumn{6}{|l|}{ Duration of physical activity, h/wk } \\
\hline Low intensity & $0.0 \pm 0.0$ & $3.5 \pm 2.8$ & $1.2 \pm 2.6$ & $1.7 \pm 2.6$ & $2.1 \pm 2.8$ \\
\hline Moderate intensity & $0.0 \pm 0.0$ & $0.0 \pm 0.0$ & $2.8 \pm 2.1$ & $1.1 \pm 2.0$ & $1.2 \pm 2.0$ \\
\hline High intensity & $0.0 \pm 0.0$ & $0.0 \pm 0.0$ & $0.0 \pm 0.0$ & $3.6 \pm 3.6$ & $0.9 \pm 2.4$ \\
\hline Frequency of exercise enough to make a sweat, /wk & $0.1 \pm 0.4$ & $1.4 \pm 2.1$ & $2.8 \pm 1.8$ & $3.5 \pm 1.9$ & $2.3 \pm 2.2$ \\
\hline Current smoker, $\%$ & 51 & 51 & 46 & 39 & 47 \\
\hline Cigarettes smoked, /d & $12 \pm 13$ & $12 \pm 13$ & $10 \pm 12$ & $9 \pm 12$ & $11 \pm 13$ \\
\hline Vegetable-poor intake, $\%$ & 34 & 15 & 13 & 11 & 14 \\
\hline Officer, $\%$ & 46 & 53 & 49 & 59 & 53 \\
\hline Body mass index, $\mathrm{kg} / \mathrm{m}^{2}$ & $23.2 \pm 2.3$ & $24.0 \pm 2.5$ & $23.5 \pm 2.4$ & $23.3 \pm 2.2$ & $23.6 \pm 2.4$ \\
\hline Total cholesterol, mg/dl & $211 \pm 40$ & $214 \pm 33$ & $214 \pm 33$ & $213 \pm 33$ & $213 \pm 33$ \\
\hline \multirow[t]{2}{*}{ Triglyceride, mg/dl } & 129 & 138 & 126 & 117 & 129 \\
\hline & [79-209] & [83-229] & [83-191] & [78-178] & [81-204] \\
\hline \multirow[t]{2}{*}{ Fasting plasma glucose, $\mathrm{mg} / \mathrm{dl}$} & 102 & 100 & 100 & 100 & 100 \\
\hline & [93-112] & [85-117] & [89-112] & [91-110] & [87-115] \\
\hline White blood cell count, /nl & $5.9 \pm 1.4$ & $5.8 \pm 1.4$ & $5.7 \pm 1.4$ & $5.4 \pm 1.4$ & $5.7 \pm 1.4$ \\
\hline Systolic blood pressure, $\mathrm{mmHg}$ & $121 \pm 14$ & $123 \pm 13$ & $122 \pm 12$ & $122 \pm 12$ & $122 \pm 13$ \\
\hline
\end{tabular}

Total cholesterol and fasting plasma glucose were presented as geometric mean values with $95 \%$ confidence interval [ ]. The other continuous variables were presented as mean $\pm \mathrm{SD}$.

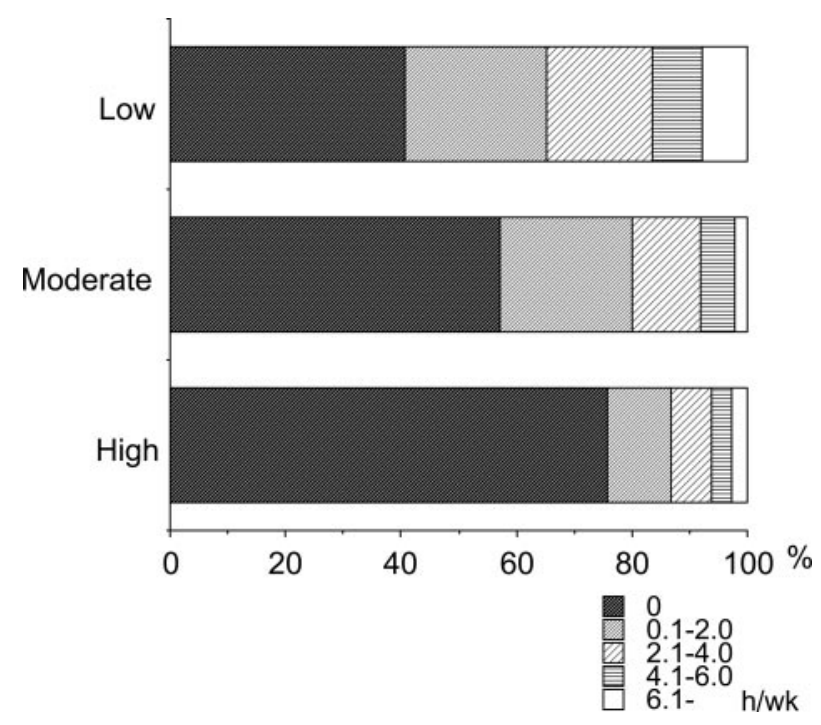

Fig. 1. Distribution of the duration of physical activity at each intensity level. $\mathrm{n}=974$.

cardiovascular and all-cause mortality beyond its contribution to "volume" of physical activity when compared to moderateintensity activity ${ }^{16,17)}$. In the present study, high intensity physical activity but not moderate or low intensity physical activity was inversely associated with the presence of obesity, hypertriglyceridemia, type 2 diabetes and hypertension (Table 4 and 5). The results are consistent with some previous studies which show that vigorous physical activity ( $>6$ METs) but not non-vigorous physical activity ( $\leq 6 \mathrm{METs}$ ) correlates with decreased mortality ${ }^{7}$ and cardiovascular disease ${ }^{3)}$.

It is suggested that there is a threshold intensity, perhaps as high as 6 METs, in addition to a minimum "volume" for the cardioprotective effects of physical activity ${ }^{16}$. However, there are also several reports which show that non-vigorous physical activity has beneficial effects for decreasing mortality and preventing cardiovascular disease ${ }^{23,25)}$. The mechanism behind the inconsistency is not clear. The effects of low intensity physical activity might be observed only in a relatively old, unhealthy or sedentary population, or might be difficult to be detected in a generally well-doing population such as SDFs personnel. Differences in the population studied and the accuracy of the information about duration and intensity of the physical activity may also affect the results. In this context, it is suggested that low or moderate physical activity is recalled less readily or precisely ${ }^{7,16)}$.

Some researchers suggest that high physical activity may prevent cardiovascular disease by reducing inflammation ${ }^{15}$. In support of this idea, markers of inflammation such as WBC count, C-reactive protein and fibrinogen are inversely associated with physical activity ${ }^{13-15)}$, whereas high WBC count is associated with increased risk of cardiovascular disease even 
Table 2. Univariate linear regression analysis of the association between duration of physical activity $(\mathrm{h} / \mathrm{wk})$ and levels of selected cardiovascular risk factors at each physical activity intensity level

\begin{tabular}{lccc}
\hline & \multicolumn{3}{c}{ Standard regression coefficient } \\
\cline { 2 - 4 } Cardiovascular risk factors & \multicolumn{3}{c}{ Intensity of physical activity } \\
& Low & Moderate & High \\
\hline Body mass index & $.099(.002)$ & $-.023(.482)$ & $-.106(<.001)$ \\
Total cholesterol & $-.043(.184)$ & $.001(.967)$ & $-.040(.214)$ \\
Triglyceride* & $-.036(.275)$ & $-.024(.453)$ & $-.153(<.001)$ \\
Fasting plasma glucose* & $-.063(.051)$ & $.006(.845)$ & $-.065(.044)$ \\
White blood cell count & $.021(.512)$ & $-.039(.221)$ & $-.110(<.001)$ \\
Systolic blood pressure & $.059(.064)$ & $-.044(.170)$ & $-.064(.045)$ \\
\hline
\end{tabular}

Standard regression coefficients. Parenthesis: P values. *The analyses for triglyceride and fasting plasma glucose were done on logarithm of them. $n=974$.

Table 3. Multivariate linear regression analysis of the association between duration of physical activity $(\mathrm{h} / \mathrm{wk})$ and levels of selected cardiovascular risk factors at each physical activity intensity level

\begin{tabular}{lccc}
\hline & \multicolumn{3}{c}{ Standard regression coefficient } \\
\cline { 2 - 4 } Cardiovascular risk factors & \multicolumn{3}{c}{ Intensity of physical activity } \\
& Low & Moderate & High \\
\hline Body mass index & $.091(.006)$ & $-.013(.693)$ & $-.099(.002)$ \\
Total cholesterol & $-.038(.244)$ & $-.009(.793)$ & $-.049(.132)$ \\
Triglyceride* & $.014(.673)$ & $-.024(.451)$ & $-.146(<.001)$ \\
Fasting plasma glucose* & $-.069(.038)$ & $-.006(.846)$ & $-.073(.027)$ \\
White blood cell count & $-.002(.951)$ & $-.013(.642)$ & $-.068(.017)$ \\
Systolic blood pressure & $.048(.142)$ & $-.048(.134)$ & $-.072(.025)$ \\
\hline
\end{tabular}

Standard regression coefficients adjusted for ethanol consumption, vegetable intake, daily number of cigarettes smoked and rank (officer/non-officer). Parenthesis: P values. *The analyses for triglyceride and fasting plasma glucose were done on logarithm of them. $\mathrm{n}=974$.

in normal range $(>7,000 / \mu \mathrm{l})^{26}$. In the present study, duration of high intensity physical activity but not that of moderate or low intensity physical activity inversely correlated with WBC count (Table 2 and 4). However, the association observed between high intensity physical activity and WBC count may be attributed to cigarette smoking, since the association was largely attenuated when daily number of cigarettes smoked was added to the analysis model (Table 3 and 5).

Duration of physical activity did not correlate with the levels of total cholesterol or the presence of hypercholesterolemia at any intensity physical activity level. These results are consistent with the findings reported to date ${ }^{9,10)}$. It has been shown that physical activity is associated with elevated HDL-cholesterol levels ${ }^{9,10)}$.

One of the limitations of the present study is its crosssectional design. Although we have taken into account several lifestyle factors in the logistic regression analysis model, other factors might have confounded the results. Subjects with diabetes, hypertension or obesity are likely to do low intensity exercise more frequently than those without them. This would attenuate the association between low intensity physical activity and cardiovascular risk factors. Thus, the paradoxical (positive) association observed between low intensity physical activity, obesity and hypertension (Table 4 and 5) may partly be explained on the basis of the health-conscious behavior.

Another demerit is that assessment of the intensity of the physical activity is solely based on the types of physical activity performed. This would increase the misclassification of intensity or duration of the physical activity. Since the population studied consists of well doing subjects, the obtained findings may not be applied to general population or physically inactive subjects. A recent randomized controlled intervention trial shows that aerobic physical exercise has no effects on progression of atherosclerosis in middle-aged white men ${ }^{27}$. Since exercise is known to increase anaerobic threshold ${ }^{28}$, the threshold may be elevated in a physically active population such as SDFs personnel. This would attenuate the effects of low to moderate exercise on metabolic parameters. 
Table 4. Odds ratio per an increment in physical activity duration $(\Delta 1 \mathrm{~h} / \mathrm{wk})$ for the presence of cardiovascular risk factors

\begin{tabular}{lccc}
\hline \multirow{2}{*}{ Cardiovascular risk factors } & \multicolumn{3}{c}{ Intensity of physical activity } \\
\cline { 2 - 4 } & OR $(95 \% \mathrm{CI})$ & Moderate & High \\
& $1.10(1.06-1.17)$ & $.95(.88-1.03)$ & $.87(.80-.96)$ \\
Obesity & {$[<.001]$} & {$[.182]$} & {$[.003]$} \\
Hypercholesterolemia & $.96(.92-1.01)$ & $1.03(.97-1.10)$ & $1.01(.95-1.06)$ \\
Hypertriglyceridemia & {$[.090]$} & {$[.364]$} & {$[.805]$} \\
& $1.03(.98-1.08)$ & $.95(.89-1.02)$ & $.87(.80-.95)$ \\
Type 2 diabetes & {$[.197]$} & {$[.157]$} & {$[.001]$} \\
& $1.07(1.01-1.13)$ & $.98(.89-1.08)$ & $.85(.74-.97)$ \\
High WBC count & {$[.020]$} & {$[.678]$} & {$[.016]$} \\
Hypertension & $1.00(.95-1.06)$ & $1.00(.92-1.08)$ & $.91(.82-1.00)$ \\
& {$[.922]$} & {$[.952]$} & {$[.048]$} \\
& $1.06(1.01-1.11)$ & $.89(.81-.98)$ & $.91(.83-1.00)$ \\
& {$[.026]$} & {$[.017]$} & {$[.044]$} \\
\hline
\end{tabular}

Univariate logistic regression analysis. [ ]: P values. Abbreviation: OR, odds ratio; CI, confidence interval. $\mathrm{n}=974$.

Table 5. Odds ratio per an increment in physical activity duration $(\Delta 1 \mathrm{~h} / \mathrm{wk})$ for the presence of cardiovascular risk factors

\begin{tabular}{lccc}
\hline & \multicolumn{3}{c}{ Intensity of physical activity } \\
\cline { 2 - 4 } Cardiovascular risk factors & Low & Moderate & High \\
& OR $(95 \% \mathrm{CI})$ & OR $(95 \% \mathrm{CI})$ & OR $(95 \% \mathrm{CI})$ \\
\hline Obesity & $1.10(1.05-1.16)$ & $.97(.89-1.05)$ & $.88(.81-.97)$ \\
Hypercholesterolemia & {$[<.001]$} & {$[.390]$} & {$[.007]$} \\
Hypertriglyceridemia & $.97(.92-1.02)$ & $1.02(.96-1.09)$ & $1.00(.95-1.06)$ \\
& {$[.211]$} & {$[.496]$} & {$[.973]$} \\
Type 2 diabetes & $1.02(.97-1.07)$ & $.95(.88-1.02)$ & $.88(.81-.95)$ \\
High WBC count & {$[.466]$} & {$[.185]$} & {$[.002]$} \\
Hypertension & {$[.06(1.00-1.12)$} & $.99(.90-1.09)$ & $.87(.76-.99)$ \\
& $.99(.93-1.05)$ & $1.02(.94-1.12)$ & $.95(.86-1.04)$ \\
& {$[.667]$} & {$[.628]$} & {$[.288]$} \\
& $1.04(.99-1.10)$ & $.89(.81-.98)$ & $.90(.82-.99)$ \\
& {$[.122]$} & {$[.015]$} & {$[.037]$} \\
\hline
\end{tabular}

Multivariate logistic regression analysis. Adjusted for ethanol consumption vegetable intake, daily number of cigarettes smoked and rank (officer/non-officer). [ ]: P values. Abbreviation: OR, odds ratio; $\mathrm{CI}$, confidence interval. $\mathrm{n}=974$.

In addition, the rank in SDFs (officer/non-officer) and subspecialty in jobs may affect the association between physical activity and cardiovascular risk factors. But, inclusion of the rank into the multivariate analysis model did not affect the association between physical activity and cardiovascular risk factors in the present study. Since we do not have the precise information about the subspecialty in jobs of the subjects, we could not take it into account in the analysis.

In conclusion, high intensity physical activity may have beneficial effects on traditional cardiovascular risk factors including body mass index, triglyceride, fasting plasma glucose and systolic blood pressure in the middle-aged relatively healthy men. The effects of low or moderate intensity physical activity on cardiovascular risk factors were much less conspicuous in the population studied.

\section{References}

1) Booth FW, Gordon SE, Carlson JC, Hamilton MT (2000) Waging war on modern chronic diseases: primary 
prevention through exercise biology. J Appl Physiol 88, 774-87.

2) Shephard RJ, Balady GJ (1999) Exercise as cardiovascular therapy. Circulation 99, 963-72.

3) Lakka TA, Venalainen JM, Rauramaa R, Salonen R, Tuomilehto J, Salonen JT (1994) Relation of leisure-time physical activity and cardiorespiratory fitness to the risk of acute myocardial infarction in men. N Engl J Med 330, 1549-54.

4) Manson JE, Hu FB, Rich-Edwards JW, Colditz GA, Stampfer MJ, Willett WC, Speizer FE, Hennekens CH (1999) A prospective study of walking as compared with vigorous exercise in the prevention of coronary heart disease in women. N Engl J Med 341, 650-8.

5) Tanasescu M, Leitzmann MF, Rimm EB, Willett WC, Stampfer MJ, Hu FB (2002) Exercise type and intensity in relation to coronary heart disease in men. $\mathrm{J}$ Am Med Assoc 288, 1994-2000.

6) Paffenbarger RS Jr, Hyde RT, Wing AL, Hsieh C-C (1986) Physical activity, all-cause mortality, and longevity of college alumni. N Engl J Med 314, 605-13.

7) Lee I-M, Hsieh C-C, Paffenbarger RS Jr (1995) Exercise intensity and longevity in men. The Harvard Alumni Health Study. J Am Med Assoc 273, 1179-84.

8) Wood PD, Stefanick ML, Williams PT, Haskell WL (1991) The effects on plasma lipoproteins of a prudent weightreducing diet, with or without exercise, in overweight men and women. N Engl J Med 325, 461-6.

9) Wannamethee SG, Shaper AG, Alberti KG (2000) Physical activity, metabolic factors, and the incidence of coronary heart disease and type 2 diabetes. Arch Intern Med 160, 2108-16.

10) Kraus WE, Houmard JA, Duscha BD, Knetzger KJ, Wharton MB, McCartney JS, Bales CW, Henes S, Samasa GP, Otvos JD, Kulkarni KR, Slentz CA (2002) Effects of the amount and intensity of exercise on plasma lipoproteins. N Engl J Med 347, 1483-92.

11) Paffenbarger RS Jr, Wing AL, Hyde RT, Jung DL (1983) Physical activity and incidence of hypertension in college alumni. Am J Epidemiol 117, 245-57.

12) Blair SN, Goodyear NN, Gibbons LW, Cooper KH (1984) Physical fitness and incidence of hypertension in healthy normotensive men and women. J Am Med Assoc 252, 487-90.

13) Nieto FJ, Szklo M, Folsom AR, Rock R, Mercuri M (1992) Leukocyte count correlates in middle-aged adults: the Atherosclerosis Risk in Communities (ARIC) Study. Am J Epidemiol 136, 525-37.

14) Geffken DF, Cushman M, Burke GL, Polak JF, Sakkinen PA, Tracy RP (2001) Association between physical activity and markers of inflammation in a healthy elderly population. Am J Epidemiol 153, 242-50.

15) Abramson JL, Vaccarino V (2002) Relationship between physical activity and inflammation among apparently healthy middle-aged and older US adults. Arch Intern Med 162, 1286-92.

16) Shephard RJ (2001) Absolute versus relative intensity of physical activity in a dose-response context. Med Sci Sports
Exerc 33, S400-20.

17) Lee IM, Skerrett PJ (2001) Physical activity and all-cause mortality: what is the dose-response relation? Med Sci Sports Exerc 33, S459-71, 93-4.

18) Examination Committee of Criteria for 'Obesity Disease' in Japan. Japan Society for the Study of Obesity (2002) New Criteria for 'Obesity Disease' in Japan. Circ J 66, 987-92.

19) WHO Consultation (1999) Definition, Diagnosis and Classification of Diabetes Mellitus and its Complications. Part 1: Diagnosis and Classification of Diabetes Mellitus. WHO, Geneva.

20) Chobanian AV, Bakris GL, Black HR, Cushman WC, Green LA, Izzo JL Jr, Jones DW, Materson BJ, Oparil S, Wright JT Jr, Roccella EJ; National Heart, Lung, and Blood Institute Joint National Committee on Prevention, Detection, Evaluation, and Treatment of High Blood Pressure; National High Blood Pressure Program Coordinating Committee (2003) The seventh report of the Joint National Committee on prevention, detection, evaluation, and treatment of high blood pressure: the JNC 7 report. J Am Med Assoc 289, 2560-72.

21) Pate RR, Pratt MP, Blair SN, Haskell WL, Macera CA, Bouchard C, Buchner D, Ettinger W, Heath GW, King AC, Kriska A, Leon AS, Marcus BH, Morris J, Paffenbarger RS Jr, Patrick K, Pollock ML, Rippe JM, Sallis J, Wilmore JH (1995) Physical activity and public health. A recommendation from the Centers for Disease Control and Prevention and the American College of Sports Medicine. J Am Med Assoc 273, 402-7.

22) Ainsworth BE, Haskell WL, Leon AS, Jacobs DR Jr, Montoye HJ, Sallis JF, Paffenbarger RS Jr (1993) Compendium of physical activities: Classification of energy costs of human physical activities. Med Sci Sports Exerc 25, 71-80.

23) Leon AS, Connett J, Jacobs DR Jr, Rauramaa R (1987) Leisure-time physical activity levels and risk of coronary heart disease and death. The Multiple Risk Factor Intervention Trial. J Am Med Assoc 258, 2388-95.

24) Manson JE, Nathan DM, Krolewski AS, Stampfer MJ, Willett WC, Hennekens CH (1992) A prospective study of exercise and incidence of diabetes among US male physicians. J Am Med Assoc 268, 63-7.

25) Slattery ML, Jacobs DR Jr, Nichaman MZ (1989) Leisure time physical activity and coronary heart disease death. the US Railroad Study. Circulation 79, 304-11.

26) Friedman GD, Klatsky AL, Siegelaub AB (1974) The leukocyte count as a predictor of myocardial infarction. N Engl J Med 290, 1275-8.

27) Rauramaa R, Halonen $P$, Vaisanen S, Lakka TA, SchimdtTrucksass A, Berg A, Penttila IM, Rankinen T, Bouchard C (2004) Effects of aerobic physical exercise on inflammation and atherosclerosis in men: The DNASCO Study. A six-year randomized, controlled trial. Ann Intern Med 140, 1007-14.

28) Wasserman K (1984) The anaerobic threshold measurement to evaluate exercise performance. Am Rev Respir Dis 129, S35-40. 